\title{
El castigo de las injurias causadas a los indios. Una página característica de Diego de Avendaño
}

\section{The punishment of the offences caused to the Indians. A typical page of Diego de Avendaño}

\author{
Francisco CUENA BOY \\ Catedrático de Derecho Romano \\ Departamento de Derecho Privado. Área de Derecho Romano \\ Facultad de Derecho. Universidad de Santander \\ cuenafj@unican.es
}

Recibido: 2 de noviembre de 2011

Aceptado: 18 de enero de 2012

\section{RESUMEN}

Ni el supuesto positivismo de Avendaño, ni su probabilismo ni el casuismo indiano dan una explicación suficiente del empeño puesto por el jesuita en desvirtuar una cédula de Felipe II que ordenaba castigar a los españoles culpables de injurias contra los indios con más rigor que si fuesen ellos víctimas del delito. Tampoco se trata de un caso que se pueda englobar en la práctica del «se acata, pero no se cumple». Lo que en realidad defiende Avendaño, con más palabras que argumentos, es el incumplimiento de la ley.

PALABRAS CLAVE: Diego de Avendaño, indios, injurias, discriminación positiva.

\begin{abstract}
Neither Avendaño's supposed positivism, nor his probabilism or the indian casuism give a sufficient explanation of the determination put by the Jesuit in invalidating a law of Philip II that orders to punish the Spanish guilty of offences against the Indians with more rigor than if they were victims of the crime. It is not also a case that could be included in the practice of «se acata, pero no se cumple» (the law is respected, but it is not fulfilled). What Avendaño defends actually, more with words than with arguments, it is the breach of the law.
\end{abstract}

KEYWORDS: Diego de Avendaño, indians, offences, positive discrimination.

\section{RÉSUMÉ}

Ni son presuposé positivisme ni son probabilisme, ni la casuistique indiane non plus, ne suffissent pas à justifier les efforts déployés par le jésuite Avendaño à réfuter une charte de Philippe II qui ordonnait punir aux espagnols coupables de diffamation contre les Indiens avec plus de rigueur que si ils auraient été victimes du même crime. Il ne s'agit pas non plus d'un cas qui pourrait être rangé dans la pratique $\mathrm{du}$ «obéit, mais pas satisfait ». Ce qui Avendaño signifie vraiment, avec plus de mots que des arguments, c'est une vraie violation de la loi.

MOTS CLÉ : Diego de Avendaño, Indiens, Blessures, Discrimination Affirmative. 


\section{ZUSAMMENFASSUNG}

Weder der positivistische Ansatz von Avendaño, noch sein Probabilismus oder sein Indio-Kasuismus spenden eine ausreichende Erklärung für die Beharrlichkeit des Jesuiten, eine Verordnung (cédula) Philipps II. zu entkräften, welche anordnete, die Spanier, die den Indios Unrecht zugefügt hatten, noch härter zu bestrafen, als es die Opfer ihrer Angriffe bereits ertragen mussten. Ebensowenig handelt es sich dabei um einen Fall der Praxis des «se acata, pero no se cumple», d.h. des Prinzips, wonach das Gesetz beachtet, aber nicht befolgt wird. Das was Avendaño in Wirklichkeit mit mehr Worten als Argumenten verteidigt, ist der Gesetzes-Ungehorsam.

SCHLÜSSELWÖRTER: Diego de Avendaño, Indios, Unrecht, positive Diskriminierung.

SUMARIO: 1 . La real cédula de 1593 sobre el castigo de las injurias a los indios y sus problemas. 2. Primeras razones de Avendaño sobre el tema: la preferencia por el propio gentilicio y la condición inferior de los indios. 3. Desvirtuación discursiva de un «rescripto» considerado «justo y conveniente». 4. La verdadera posición de Avendaño. 5. ¿Por qué una página «característica» del jesuita?

\section{La real cédula de 1593 sobre el castigo de las injurias a los indios y sus problemas}

Las observaciones que siguen se refieren específicamente al $\S$ II de los Complementos al título XI, capítulo I del Thesaurus Indicus de Diego de Avendaño ${ }^{1}$. La cuestión que se discute en esas páginas es "si las injurias hechas a los indios deben ser castigadas más severamente que las inferidas a otros". Avendaño la aborda en relación con una real cédula ("rescripto", la llama él) de Felipe II a la Audiencia de Lima fechada el 29 de diciembre de 1593; en ella se ordena castigar en adelante a los españoles "que injuriaren, ofendieren, o maltrataren a los indios" con mayor severidad "que si los mismos delitos se cometiessen contra los españoles"2. Se trata, así pues,

${ }^{1}$ Las referencias al Thesaurus siguen la edición y traducción en curso de Ángel Muñoz García, que ha llegado ya al vol. II. Nuestro tema se ubica en el tomo publicado con el título que indicamos más abajo en esta misma nota (Avendaño IV), donde el parágrafo referido llena las pp. 271-276, núms. 144-152; en las notas sucesivas, las citas de este $\S$ II se harán por el nombre de Avendaño seguido de la página y el número correspondientes conforme a ese tomo; el cap. 1, tít. 11 (pp. 137-141, núms. 1-6) trata de las obligaciones a que están sometidos los Protectores de Indios en el fuero de la conciencia. Otras citas del Thesaurus seguirán este sistema, siempre con los tomos de la edición de Muñoz García como referencia: Avendaño I [= Ángel Muñoz García (ed.), Diego de Avendaño. Thesaurus Indicus (1688), Pamplona, 2001, que incluye los tres primeros títulos del vol. I del Thesaurus]; Avendaño II [= Ángel Muñoz García (ed.), Oidores y oficiales de hacienda. Thesaurus Indicus, vol. I, Tít. IV y V, Pamplona, 2003]; Avendaño $I V$ [ = Ángel Muñoz García (ed.), Mineros de Indias y Protectores de Indios. Thesaurus Indicus, vol. I, Tít. X-XI y complementos, Pamplona, 2009]; y Avendaño V [= Ángel Muñoz García, Privilegios de los indios. Thesaurus Indicus, vol. II, Tít. XII, c. I-X, Pamplona, 2010]; en cada caso se señalará la página y el número que correspondan. Por último, las introducciones del editor se citarán del modo que sigue: Muñoz García, "Introduccion" a Avendaño I (o II, o IV).

${ }^{2}$ La real cédula en cuestión figura en el Cedulario de Encinas, vol. 4, p. 269, y fue recogida en la Recopilación, lib. 6, tít. 10, ley 21; la recuerdan Juan Solórzano Pereira, Política Indiana, lib. 2, cap. 28, núms. 12 y ss., cuya exposición tendremos también en cuenta, y Alonso de la Peña Montenegro, Itine- 
de un tema de orden jurídico-penal que prima facie parece presentarse bajo el aspecto modernísimo de la discriminación llamada positiva. En el caso que nos ocupa, el telón de fondo de tal privilegio ${ }^{3}$ se encuentra en la condición jurídica de personas miserables en la que los indígenas quedaron inscritos (y recluidos) durante la colonia con el bondadoso designio de favorecerlos y ampararlos ${ }^{4}$.

La primera pregunta que debemos hacernos se refiere a la necesidad de discutir el punto si ya la real cédula mencionada parecía haberlo decidido con suficiente claridad. Nos da una pista cierto suceso recordado por Solórzano Pereira y Peña Montenegro; a saber, que el gobernador del Cuzco don Gabriel Paniagua de Loaysa mandó cortar la mano a un español que en su presencia había dado una bofetada a un cacique ${ }^{5}$. Ambos escritores subrayan que el castigo se impuso de conformidad con la disposición real y en ejecución de la misma; pero el primero alaba tanto la firmeza del gobernador -su suegro, por otro lado- que nos hace sospechar el carácter excepcional del caso, subrayado ya por el hecho de que el cacique hubiera sido agredido en presencia del propio don Gabriel; todo ello hubo de suceder, además, durante la segunda gobernación de éste en Cuzco, que cae hacia 1596, y por tanto, probablemente, a no mucha distancia de la promulgación de la norma. Pero ni siquiera es necesario sospechar nada: un poco más adelante, el propio Solórzano señala que la cédula se respetaba poco y se aplicaba mal ${ }^{6}$, de ahí la necesidad de seguir insistiendo en la necesidad de cumplirla tanto tiempo después de haber sido promulgada.

Ahora bien, ¿cuáles habían sido y seguían siendo las razones de su inocultable fracaso? A tenor de lo que el propio Solorzano nos cuenta, podemos intuir que el carácter discriminatorio de la norma contrariaba no ya una idea de igualdad general de

rario para párrocos de indios, lib. 2, trat. 1, sec. 1, núm. 1 in fine; cfr.Paulino Castañeda Delgado, "La condición miserable del indio y sus privilegios", en Anuario de Estudios Americanos 28 (1971) pp. 265 s.; Antonio Dougnac Rodríguez, Manual de historia del derecho indiano, México, 1994, p. 323.

${ }^{3}$ Privilegio recogido por Gaspar Escalona y Agüero en su proyecto de "Código Peruano" (hacia 1635): vid. Castañeda Delgado, op. cit., p. 82: "Privilegio 33. La injuria y maleficio hecho a Indios se debe castigar con maior rigor que si fuesse hecho a españoles".

${ }^{4}$ Para una primera orientación, vid. Francisco Cuena Boy, s.v. Miserabiles personae, en Diccionario Histórico Judicial de México: Ideas e Instituciones, tomo 2, México, 2010, pp. 1094-1098. Hablando de su ratio decidendi, Solórzano Pereira, lib. 2, cap. 28, núm. 12, dice que la real cédula "se debe tener por justa respecto del favor y amparo que se pretende hacer y dar a estos desventurados [los indios]" y añade un argumento que halagará sin duda los oídos de nuestros más modernos reformistas: "Y cuanto más se frecuenta el injuriarlos y maltratarlos, tanta mayor necesidad hubo de que la ley se pusiese de su parte y mandase castigar con mayor rigor a los que en esto excediesen"; lo que quizá no les satisfaga tanto es que pueda apoyarse para decir esto en viejos textos de ambos derechos: D. 37.10.1.5 (Ulp. 41 ad ed.): nam vel magis consulendum est his quibus maius periculum intenditur; VI 1.6.3: Ubi periculum maius ostenditur, ibi procul dubio est plenius consulendum; porque el hallazgo resulta no ser tan nuevo y porque el mérito del mismo pertenece a un pensamiento "antiguo" que querrían ver arrumbado; pero, en fin, Solórzano es Solórzano y nuestras querellas no eran las de él.

${ }^{5}$ Solórzano Pereira, lib. 2, cap. 28, núm. 15, y Peña Montenegro, lib. 2, trat. 2, sec. 1, núm. 1; Solórzano precisa que la bofetada fue grande y propinada "sin causa bastante".

${ }^{6}$ Solórzano Pereira, lib. 2, cap. 28, núm. 20. 
trato, extraña como tal a las concepciones sociales y jurídicas de la época, sino un sentimiento muy profundo de los españoles que los hacía verse, sin distinción alguna, como nobles en comparación con los indios ${ }^{7}$. Dicho sentimiento determinaba una actitud de resistencia a colocar en ningún caso a ningún indio por encima de ningún español, actitud a la que no serían ajenas tampoco las propias autoridades españolas. Y lo que ordenaba la cédula de 1593 era hacer precisamente lo que acabamos de decir y en un tipo de asuntos que, por si fuera poco, tocaban de lleno a la estima y el honor. Los indios, sabedores de que no había freno eficaz a las "injurias e insolencias" que les hacían los españoles, las solían disimular; también por miedo a sufrirlas aún mayores de los que hubieran debido ampararlos y aplicar la ley ${ }^{8}$. Siempre que podían, y por lo que parece podían casi siempre, los españoles se mantenían en sus trece y tratadistas hubo que les daban la razón. Solórzano menciona dos: Fernando Zurita y Baltasar Gómez de Amescua. El primero, basándose en Santo Tomás, admitía que también los indios pueden tener "verdadera nobleza y verdadero y propio derecho a su fama y hacienda", pero "a su modo", por lo que el castigo de las injurias que reciben de los españoles debe ser menos riguroso que el practicado entre éstos, toda vez que los indios son "de más baja y humilde condición... y no se curan mucho de estas injurias, ni se alteran ni enojan gravemente si las reciben"; agregaba Zurita, en la misma dirección, el uso jurídico de graduar la gravedad de la ofensa según la calidad de la persona que la recibe ${ }^{9}$. El segundo explicaba mediante una comparación de carácter histórico el hecho de que, entre los indios, "los más viles españoles se tienen y reputan por más dignos de honra y estimación que los más nobles indios"10.

En cualquier caso, Solórzano está lejos de compartir estos argumentos y se acoge a las razones por las que la cédula "mandó lo contrario tan expresamente como se ha visto"11. Y aunque echa mano también del uso jurídico alegado por Zurita, no lo hace para contradecir la ley, sino para subrayar su justificación todavía mayor cuando la injuria es inferida a un cacique o indio principal ${ }^{12}$.

Esto último vuelve a situarnos por un momento ante la noticia del cacique abofeteado por un español en Cuzco, suceso del cual queremos destacar tres datos que nos parecen importantes: gran bofetada, cacique (“cacique noble”: Peña Montenegro) y

\footnotetext{
${ }^{7}$ Algo semejante dice Muñoz García, "Introducción" a Avendaño IV, p. 32, donde destaca que la consideración del indio como miserable venía a ser "como el sello oficial y reconocimiento de la superioridad con que los colonos se veían respecto a los indígenas".

${ }^{8}$ Solórzano Pereira, lib. 2, cap. 28, núm. 15.

${ }^{9}$ Vid. Solórzano Pereira, lib. 2, cap. 28, núm. 18; la obra de Fernando de Zurita, Theologicarum de indis quaestionum enchiridion primum, Matriti, 1586, es anterior a nuestra real cédula.

${ }^{10}$ Solórzano Pereira, lib. 2, cap. 28, núm. 19, en referencia al Tractatus de potestae in se ipsum, Mediolani, 1609, de Baltasar Gómez de Amescua.

${ }^{11}$ Solórzano Pereira, lib. 2, cap. 28, núm. 20.

12 "[P] $]$ orque la calidad de la persona aumenta el delito, como lo enseña el derecho", y cita D. 48.19.16.1 (Claud. Sat. lib. sing. de poen. pag.) e I. 4.4.9: Solórzano Pereira, lib. 2, cap. 28, núm. 14; cfr. también Gai. Inst. 3.225, D. 47.10.7.8 (Ulp. 57 ad ed.).
} 
presencia del gobernador. Según D. 48.19.16.1, primer texto de los dos citados por Solórzano a este respecto, la gravedad de un delito se determina de varios modos que influyen en la pena, entre otros, teniendo en cuenta la persona, el lugar y la calidad del hecho; como informa I. 4.4.9, ex facto, ex loco y ex persona son también los criterios en virtud de los cuales la inuria recibe la calificación de atrox en el régimen de la actio iniuriarum aestimatoria ${ }^{13}$. Pues bien, pensamos que la injuria que sufrió aquel cacique pudo considerarse grave (atrox) por la confluencia de los tres criterios: ex facto, porque fue golpeado y, aunque una sola vez, con fuerza tan grande como para ser recordada y mencionada; ex loco, porque el hecho tuvo lugar ante el gobernador (in conspectu praetoris, señala por vía de ejemplo el texto de las Instituciones justinianeas); y ex persona, porque se trataba de un indio principal y su agresor era un español cualquiera (un soldado según Peña Montenegro).

El cacique abofeteado tuvo suerte: su agresor fue castigado y cabe la conjetura de que la pena que le impuso el gobernador tuvo en cuenta no sólo el mandato de la cédula filipina de 1593, sino también un conjunto excepcional de circunstancias que aconsejaban cargar la mano en el castigo.

\section{Primeras razones de Avendaño sobre el tema: la preferencia por el propio gentilicio y la condición inferior de los indios}

¿Y Diego de Avendaño? Para empezar, nuestro jesuita dedica al tema bastante más espacio que Solórzano, lo que es seña de la importancia que tiene para él; pero, a diferencia del propio Solórzano, lo trata y lo decide sin cita directa de fuente jurídica ninguna. Además, como vamos a ver, imprime a su solución un sello muy distinto y personal que, no sin pagar el precio de una considerable ambigüedad, se aparta a la chita callando de la opinión de aquél. ¿Debemos ver en ello una especie de claudicación ante la terca realidad? ¿quizá mejor otro ejemplo -uno más- de adaptación posibilista al perfil irreductible de los hechos? ¿cuánta es no obstante la diferencia entre lo uno y lo otro? Veamos cómo razona nuestro autor.

Lo primero que hace Avendaño, inmediatamente después de transcribir la cédula de 1593, es objetar frontalmente su mandato mediante la propuesta de una ratio alternativa, lo que parece anunciar el propósito de sentar la discusión sobre bases completamente diferentes: dado que "hay que atender más al propio gentilicio que al extraño, pues aquél es más próximo", si el Rey quisiera establecer alguna desigualdad de trato, ésta debería ser en beneficio de los españoles; caso de no hacerlo así, al menos debería mantener "la misma equidad que exige la justicia". Este término, equidad, de por sí ambiguo, es aquí menos impreciso de lo que parece, pues significa sim-

\footnotetext{
${ }^{13}$ Sobre el concepto de iniuria atrox, vid. Matthias Hagemann, Iniuria. Von den XII-Tafeln bis zur Justinianischen Kodifikation, Köln-Weimar-Wien, 1998, pp. 91 ss.; Dora de Lapuerta Montoya, Estudio sobre el edictum de adtemptata pudicitia, Valencia, 1999, pp. 57 ss.
} 
plemente igualdad: "para que se conserve la igualdad de la justicia", dice un poco más adelante el jesuita. En consecuencia, lo mínimo que Avendaño admite en este asunto es la igualdad de trato para indios y españoles, posición que excluye por injusta toda discriminación favorable a los primeros ${ }^{14}$.

Un segundo argumento es la «opinión común entre los autores» de que ha de atenderse a la calidad de las personas de modo de guardar, en la compensación por injurias, la proporción que indica la desigual condición de los diferentes individuos. Es de advertir que la palabra compensación utilizada por el jesuita alude a un concepto distinto del de pena -como se verá más claramente hacia el final de la exposición de Avendaño-, cuando sabemos que lo único que la disposición de 1593 ordenaba agravar expresamente en las ofensas de españoles contra indios era lo segundo, o sea, el castigo por el delito. Quizás una consideración más atenta de la diferencia entre los dos planos hubiera podido matizar el desapego de nuestro autor hacia esa norma. De cualquier modo, el hecho de no haberlos distinguido no tiene consecuencias inmediatas, ya que el discurso, pese a utilizar el término, no se refiere de momento a la compensación sino a las penas, y así también, cuando señala que los indios "son de condición inferior en comparación a los españoles", esta indicación se limita a ellas ${ }^{15}$. Se notará, por lo demás, que este segundo argumento no camina a la par con el primero: ambos apoyan un trato favorable a los españoles pero por razones bien distintas y el segundo, en concreto, por las mismas que expusieran Zurita y Gómez de Amescua, recordados por Avendaño a través de la mención que hace de ellos Solórzano Pereira ${ }^{16}$.

Estos dos primeros argumentos se adoban inicialmente con algunos pasajes de las Sagradas Escrituras - concretamente los versículos 12-27 del cap. 21 del libro del Éxodo - más dos citas doctrinales de las que podemos prescindir; el segundo se completa con un texto de Aulo Gelio relativo a la penalidad de las iniuriae en las antiguas leyes romanas. La forma en que Avendaño engarza los pasajes bíblicos en su exposición no deja de ser curiosa: la preferencia por el propio gentilicio (o sea, por los españoles) se contrarresta con el v. 12, que quiere que la ley contra el homicidio sea general, y con el 20, que incluye en ese crimen el hecho de matar a un esclavo sin prever pena distinta. De aquí resulta la necesidad de conservar "la igualdad de la justicia", y esto es suficiente para desautorizar el trato de favor hacia los indios por lo menos en asuntos de índole penal. El paso hacia la proporcionalidad basada en la desigual condición de las personas - un paso que, si bien se mira, rompe con la igualdad o equidad que se acaba de afirmar-se da con ayuda de los vv. 26-27, donde, en relación con el talión

\footnotetext{
14 "Por tanto viola la equidad de la justicia respecto a las injurias el que en ello establece razón distinta para indios y españoles, como para que deban ser castigados más gravemente los injustos daños de aquéllos que los de éstos": Avendaño, p. 272, núm. 145. Sobre la apelación de Avendaño al "gentilicio español”, cfr. Muñoz García, "Introducción” a Avendaño $I V$, pp. 32 ss., que la pone en relación con el concepto de clientela al que el jesuita recurrírá después; pero vid. infra nuestra discusión.

${ }^{15}$ Avendaño, p. 272, núm. 145.

${ }^{16}$ Avendaño, p. 273, núms. 145 y 146.
} 
(vv. 23 ss.), se dispone de modo distinto respecto a los esclavos. Podría llamarnos la atención que la ley del talión, expresamente abolida por Cristo (Mt. 5.38-39), se siga utilizando como topos argumentativo, pero esto no es lo más importante. Lo principal es que este bucle de su raciocinio conduce a Avendaño a una comparación implícita de los indios con los esclavos, que no tiene nada que ver con la condición jurídica de los primeros (vasallos libres de la Corona, como es bien sabido), y que el jesuita, consciente de este deslizamiento, se apresura a deshacer. No del todo, sin embargo, porque de esa comparación retiene la idea de inferioridad de los indios frente a los españoles ${ }^{17}$, cuya consecuencia -el trato desigual en desventaja de los indios- pretende luego acreditar con una noticia de Aulo Gelio acerca de la pena prevista para el os fractum por la ley de las XII Tablas ${ }^{18}$. Ahora bien, mientras sigue hablando de libres y esclavos, el pasaje de las Noches Áticas que trae a colación sólo indica que los romanos castigaron las injurias más graves (iniuriae atrociores) con mayor severidad, pero no menciona la diferencia efectiva de las penas establecidas por la ley para el os fractum según fuera la víctima un libre o un esclavo ${ }^{19}$, de manera que ese pasaje no ofrece a la conclusión de Avendaño el respaldo que busca en él. No obstante lo cual, el jesuita no se da por vencido: "La causa de ello ha de ponerse en la condición más baja; por lo que se atiende a ella cuando alguien infiere una injuria a un esclavo ajeno. Lo mismo habrá que sostener, por tanto, en nuestro caso" 20 .

Nuestro autor coincide con Solórzano en que la causa de que "el citado rescripto Real" (la cédula de 1593) se practique poco es quizás esta inferioridad ${ }^{21}$. En cambio, no recoge con fidelidad el pensamiento del oidor cuando declara a éste conforme con la idea de que a los indios se les debe menor compensación en virtud de su "cualidad". Como ya hemos dicho ${ }^{22}$, Solórzano consideraba discursivamente esta posibilidad, pero su conclusión se atiene estrechamente a lo ordenado por la ley.

\section{Desvirtuación discursiva de un «rescripto» considerado «justo y conveniente»}

Teniendo en cuenta la continuación del raciocinio ${ }^{23}$, podemos tomarnos lo anterior como una aproximación preliminar al tema, como si Avendaño hubiera querido cen-

17 "Los indios, aunque no sean esclavos, son de condición inferior en comparación a los españoles": Avendaño, p. 272, núm. 145.

18 A. Gell., Noct. Att. 20.1.32: Sed iniurias atrociores, ut de osse fracto, non liberis modo, verum etiam servis factas inpensiore damno vindicaverunt; vid. Avendaño, pp. 272 s., núm. 145. Este pasaje de Gelio, como las otros que serán citados más adelante, pertenece a la famosa Disceptatio Sex. Caecilii iureconsulti et Favorini philosophi de legibus duodecim tabularum.

${ }^{19}$ Cfr. lex XII Tab. 8.3: Manu fustive si os fregit libero, CCC, si servo, CL poenam subito; Gai. Inst. 3.223 .

${ }^{20}$ Avendaño, pp. 272 s., núm. 145.

${ }^{21}$ Avendaño, p. 273, núm. 146.

${ }^{22}$ Vid. supra.

${ }^{23}$ Y la forma en que comienza: “Sostengo, en primer lugar”: Avendaño, p. 273, núm. 147. 
trarlo antes de darnos sus verdaderos argumentos. De todos modos, esos argumentos verdaderos que pasa a exponer ahora tendrán que adaptarse - para hacerle sitio de la forma que vamos a ver- a la idea ya adquirida y cardinal de la inferioridad de los indígenas y a sus consecuencias contrarias a la ley.

"El rescripto citado es justo y conveniente", afirma paradójicamente el jesuita. La primera razón es la conversión de los indios, ya que éstos "creen más a los hechos que a las palabras" y la profesión y fe cristianas se les tornarían odiosísimas si no se pusiera coto a las injurias de los españoles y otros europeos ${ }^{24}$; son además pacíficos e inofensivos y viven simplicísimamente. De ahí la necesidad de mayor defensa para los indígenas y la conveniencia de concretar ese plus en el rigor penal "cuando no bastan otras precauciones" 25 .

Pero además, la justicia del "rescripto" se debe también al hecho de que "los indios están bajo la cientela del Rey" (?) y las ofensas a los clientes se pueden castigar con penas mayores. Esta llamativa proposición se corrobora, en su segunda parte, mediante una nueva cita de Aulo Gelio en la que late también una referencia a las XII Tablas ${ }^{26}$. Pero, ¿y la primera parte?; más allá de que parezca facilitar cierta vestidura jurídica para el asunto, esa idea de que los indios son clientes del Rey, ¿es algo más que una invención oportunista de Avendaño? Enlazándola con la necesidad de atender más al gentilicio propio que al extraño, afirmada al comienzo del parágrafo, Muñoz García atribuye a esta idea una importancia probablemente inmerecida ${ }^{27}$; ni aun admitiendo la presencia y el peso del derecho romano que este autor supone, y supone bien, todavía en época de nuestro jesuita ${ }^{28}$. Mejor jurista que éste, Solórzano no menciona la clientela ni la necesita para nada a la hora de explicar la condición de inferioridad de los indígenas, que es desventaja de hecho mucho antes que fruto de una relación jurídica. Por otro lado, inevitablemente, las consecuencias de la concepción de los indios como clientes del Rey habrían sobrepasado los límites del tema en discusión y hubieran debido afectar en su conjunto a la ordenación de la República de Indios, determinando una especie de "estado clientelar" de cuya realidad cabría esperar otras huellas en el Thesaurus, que sin embargo no las contiene. Los mismos protectores de indios no se presentaban ni eran entendidos bajo la figura de patronos sino bajo la de tutores de los

\footnotetext{
${ }^{24}$ Se apoya Avendaño en una disposición del II Concilio Limense que, de todos modos, no se refiere a los indios en general sino sólo a los curacas.

${ }^{25}$ Avendaño, pp. 273 s., núm. 147.

${ }^{26}$ A. Gell., Noct. Att. 20.1.40: sic clientem in fidem acceptum cariorem haberi quam propinquos tuendumque esse contra cognatos censuit, neque peius ullum facinus existimatum est, quam si qui probaretur clientem divisui habuisse; cfr. lex XII Tab. 8.21: Patronus si clienti fraudem fecerit, sacer esto.

${ }^{27}$ Vid. Muñoz García, "Introducción" a Avendaño IV, pp. 32 ss.; en la misma línea, para José Carlos Ballón, "Diego de Avendaño y el probabilismo peruano del siglo XVII", en Revista de Filosofía 60 (2008-3), p. 39, "[e]l relato de Avendaño parece apelar en su lectura del Perú a dos sujetos categoriales extraídos del antiguo Derecho Romano: ‘clientes' y 'vernáculos'. El primero sirve para caracterizar la relación establecida por los indios con el poder y alude a una relación social específica de "clientelaje"”. ${ }^{28}$ Cfr. Muñoz García, "Introducción" a Avendaño IV, pp. 32 y 37.
} 
naturales. Por este conjunto de razones, podemos admitir que el jesuita, al introducir el concepto de clientela, tuviera la intención específica de reforzar aquella otra noción, que ha venido defendiendo desde el principio, de la inferior condición de los indígenas. Pero el uso de un tal concepto (queremos decir el de clientela) es de carácter netamente tópico y no, de ninguna forma, sistemático. Más aún, no se comprende bien el iter mental del jesuita, que por segunda vez -le hemos visto hacerlo antes, en efecto, cuando sacrificó la "igualdad de la justicia" a la "opinión común" de los autores- renuncia a la consecuencia explícita de su argumento -a saber, la que él mismo ha dicho: "las ofensas de los clientes pueden castigarse con mayor pena que las de los otros"para seguir avanzando hacia un resultado que no consiste, ni mucho menos, en la aceptación incondicional de lo ordenado en 1593 por Felipe II.

Llegará sin duda a ese resultado, queda ya poco para verlo, pero antes presenta otro argumento en supuesto respaldo de la ley: "Cuando un gran beneficio de la república aumenta con perjuicio de alguno de los otros, se está en facultad de prestarle ayuda" ${ }^{29}$. ¿Qué significa esta frase? Sencillamente, que si no se vela por ellos, los indios se acabarán y con ellos se perderán los "grandes tesoros de oro y plata con los que se enriquece todo el mundo..." ${ }^{30}$. Un argumento que conviene comparar con el que trae Solórzano ${ }^{31}$ acerca de la importancia de cuidar los pies (los indios) porque llevan el peso de todo el cuerpo y su caída haría peligrar "los demás miembros y aun la cabeza", sólo que el oidor lo expresa, nos parece, con bastante más elegancia por no decir con más humanidad. Extrañamente, porque no tiene nada que ver, Avendaño vuelve a citar aquí a Gelio, de quien dice que habla "a propósito de esto". Pero lo cierto es que esta nueva referencia, si se puede enlazar con algo, no es con el argumento que acabamos de exponer sino, saltando por encima de él, con el respecto de la fides que ya había hecho acto de presencia en el texto antedicho de las Noches Áticas sobre la clientela (continuación, por cierto, del que ahora se alega). Se trata, efectivamente, de aquel ejemplo extraordinario de respeto a esta virtud que dieron los romanos durante la segunda guerra púnica con la entrega de cónsules famosos al enemigo confirmandae fidei publicae causa ${ }^{32}$. De todos modos, tampoco nos parece que la tesis de los indios como clientela del Rey reciba ningún apoyo de esta noticia histórica ${ }^{33}$; más bien pensamos que ésta no tiene otro objeto que encarecer la fides, virtud

\footnotetext{
${ }^{29}$ Avendaño, p. 274, núm. 148.

${ }^{30}$ Muñoz García, "Introducción” a Avendaño $I V$, p. 36, considera muy sintomático este argumento "por el respeto a los indios".

${ }^{31}$ Solórzano Pereira, lib. 2, cap. 28, núm. 21.

${ }^{32}$ A. Gell., Noct. Att. 20.1.39-40: Omnibus quidem virtutum generibus exercendis colendisque populus Romanus e parva origine ad tantae amplitudinis instar emicuit, sed omnium maxime atque praecipue fidem coluit sanctamque habuit tam privatim quam publice. Sic consules, clarissimos viros, hostibus confirmandae fidei publicae causa dedidit; precisando más la noticia en cuestión, Avendaño cita también a Val. Max. 1.1.14, donde la peripecia del cónsul M. Atilio Régulo sirve para ilustrar la custodia religionis de los romanos, y Cic., de off. 3.99-100: sed ius iurandum conservandum putabat.

${ }^{33}$ Como parece pensar en cambio Muñoz García, “Introducción” a Avendaño IV, p. 34.
} 
pública y privada, y proponerla como norma de conducta de los españoles hacia los indios, pero no necesariamente dentro del esquema de la clientela.

\section{La verdadera posición de Avendaño}

"Se requiriría llevar a la práctica lo más posible el citado rescripto" porque es justo y conveniente y porque no se ha derivado de su aplicación ningún perjuicio, dice Avendaño ahora, en el momento de enfilar el final de su reflexión ${ }^{34}$. El condicional es sospechoso y las razones resultan poco convincentes. Con lo que lleva dicho y con lo que aún dirá, el elogio de las leyes que pone el jesuita a continuación, tomándolo de Cino da Pistoia y Casiodoro ${ }^{35}$, es incluso desconcertante: "Donde se vive con las leyes, se vive felizmente". Desde luego, pero véase lo que añade acto seguido: "Aunque así sea, creo que los indios estarán suficientemente contentos si se actúa con ellos de acuerdo al derecho común, y que sus injurias no queden impunes". ¿Acaso es necesario volver a recordar una vez más lo que ordenaba el "rescripto" de 1593 con palabras que no dejaban margen a ninguna interpretación? En realidad, Avendaño no está convencido de la conveniencia de que el "rescripto" se cumpla en sus propios términos y cuanto más mejor; él no cree en realidad que una ley que invierte los términos correctos del problema, colocando a los indios por encima de los españoles pese a ser de calidad inferior a la de ellos, pueda ser justa y conveniente, sino acaso indecorosa.

La verdadera posición de Avendaño se deduce de otro lugar del Thesaurus donde se lee lo siguiente: "No puede aprobarse la práctica según la cual reos de crímenes infames quedan libres porque se consideran más honorables debido a algún cargo más relevante desempeñado, o por pertenecer a familia libre, o porque son españoles de distinguida presencia; donde ser español o tener buena presencia se considera como un grado de superioridad frente a la turba de hombres más viles, negros, Indios y mestizos" 36 . O sea, Avendaño no quiere que los españoles que injurian a los indios queden sin castigo prevaliéndose de su superioridad, pero en el caso que nos ocupa no se trata evidentemente de esto sino de que los ofensores españoles sean castigados con mayor severidad. Y ante esta posibilidad vemos que Avendaño se repliega hacia lo que llama derecho común y se conforma simplemente con que las ofensas de los españoles a los indios no queden impunes. Esto no es admisible como interpretación de la real cédula de 1593 sino que supone el total desconocimiento de su ratio ${ }^{37}$ y de su mandato.

\footnotetext{
34 Avendaño, p. 275, núm. 149.

${ }^{35}$ Cino da Pistoia: "ubi est iustitia, est felicitas"; Cassiod., Var. 3.17.3.

${ }^{36}$ Avendaño II, p. 275, núm. 152; conviene leer todo este número y el siguiente, donde señala que, dado que las leyes no pueden tener en cuenta todas las circunstancias, "se deja al arbitrio de quien juzga la facultad de que pueda disminuir o aumentar la pena de acuerdo a la contingencia del hecho" y señala (algo para él normal) que "[e]n muchas leyes se establecen penas con discriminación de personas, y suele señalarse mayor para las personas comunes que para las nobles".

${ }^{37}$ Como se ha podido ver, la ratio que toma en consideración Avendaño es meramente el contento suficiente de los indios; compárese esta posición con la de Solórzano, resumida supra, nt. 4.
} 
La prueba de que nuestra lectura está bien encaminada nos la da el número siguiente del complemento que estamos repasando ${ }^{38}$, donde Avendaño sostiene expressis verbis que "[el] asunto se encuentra actualmente en situación en la que el rescripto no obliga, en general, cuanto al mencionado exceso" (entiéndase la "mayor severidad" ordenada por la real cédula). Y donde recomienda, si acaso, que se cumpla "a veces" en los casos de "delitos más fuertes" o en otros en los que el castigo pudiera tener valor de ejemplaridad ${ }^{39}$. Asimismo, esto prueba también que las reflexiones del jesuita, aunque giran alrededor de la ley, no se formulan con el propósito de interpretarla.

Habiendo hablado del castigo, o sea, de las penas, Avendaño regresa a última hora al tema de la compensación que ya había tocado al principio ${ }^{40}$. Y lo hace para decir que "en lo que se refiere a la compensación en materia de honor, no debe aplicarse una igualdad absoluta", pudiendo suceder incluso que la "abyecta condición de los indios de la plebe" haga innecesaria cualquier satisfacción; parece, pues, que el indio de la plebe puede llegar a carecer de cualquier "fama" merecedora de respeto y protección, también de aquella que, cabe suponer, debía pertenecerle "a su modo" ${ }^{41}$. Distinto sería el caso de los muchos indios "nobles y educados" (léase españolizados): a éstos sí habría que darles satisfacción oportuna a juicio de prudente confesor. Todo esto se refiere a aquellos casos en que "se trata solamente de palabras y no actúan las manos" ${ }^{42}$. ¿Acaso quiere decir con esto Avendaño que la fama del indio plebeyo sí es herida por la injuria física, o piensa que tampoco en tales casos hay honor que se deba compensar, sino sólo el eventual daño corporal?

El propio jesuita nos da su respuesta a esta cuestión ${ }^{43}$. No hay deber ninguno de restituir "por un honor lesionado sin ningún otro perjuicio"; tampoco si el daño corporal causado se puede curar sin gasto, como sucede habitualmente, por ejemplo, con "una bofetada, un bastonazo o una patada". A este tipo de agresiones les da el curioso e impreciso nombre de "injuria transitoria", cuya característica es que a lo sumo dejan en la víctima "una exacerbación de ánimo" 44 . La única obligación que nace de ellas es

\footnotetext{
${ }^{38}$ Avendaño, p. 275, núm. 150.

${ }^{39} \mathrm{Y}$ aquí, una nueva cita de Casiodoro: ut plus terror corrigat quam poena consumat: Cassiod., Var. 7.1.2.

${ }^{40}$ Avendaño, pp. 275 s., núm. 151.

${ }^{41}$ Vid. supra.

${ }^{42}$ Respecto de los indios "nobles y educados" habla Avendaño de proferir graves insultos contra ellos; cuando se refirió al principio al tema de la compensación, dejó ya dicho lo siguiente: "Todo esto lo decimos especialmente respecto a las injurias de honor; pero se puede aplicar a todas, ya que el motivo es el mismo": Avendaño, p. 273, núm. 146.

${ }^{43}$ Avendaño, p. 276, núm. 152, donde sigue la opinión de Luis de Molina, De iustitia et iure, trat. IV, disp. 46.

${ }^{44}$ Es oportuno traer a colación aquí una observación de Demóstenes que el jurista romano Claudio Saturnino hace suya: neque enim plaga iniuriam movit, sed contumelia: neque tam verberari ingenuis intolerabile, quamquam non tolerandum, quam verberari iniuriam... haec exacerbant, haec faciunt, ut sui compotes amplius non sint homines non adsueti opprobiis (D. 48.19.16.6, Claud. Sat. lib. sing. de poen. pag.); aunque no es imposible que Avendaño pensara que los indios eran adsueti opprobiis.
} 
la de aplacar al injuriado, y los indios se aplacan y contentan "con cualquier signo de benevolencia y no se sienten injuriados en el mismo grado que los españoles, como si fueran niños". Lo cual vale también para los "nobles y educados", que aunque dan más importancia a estas injurias, ni siquiera necesitan las disculpas del que les agravió, sino que se aplacan con "un trato afable". Siendo así que la única finalidad de la satisfacción es que el injuriado quede satisfecho, si los indios se conforman con tan poco no hay por qué darles más, concluye con descarnado realismo nuestro tratadista ${ }^{45}$.

Avendaño tenía noticia del caso de la bofetada propinada a un cacique por un español: no puede por menos que haberlo leído en la Política de Solórzano. No es difícil imaginar qué aprietos le habría supuesto si hubiese intentado encajarlo en su discurso. Quizá por esta razón lo silenció.

\section{5. ¿Por qué una página «característica» del jesuita?}

Ahora bien, ¿por qué pensamos que el $\S$ II de los Complementos al título XI, capítulo I del Thesaurus nos ofrece una página característica del jesuita, tal y como se ha postulado desde el título de este pequeño estudio? Evidentemente por el methodus que le vemos ahí utilizar. Pero antes de referirnos a esto, ¿cuál es el rasgo que nos parece más sobresaliente del modo de discurrir que nos presenta dicho parágrafo? $\mathrm{Su}$ naturaleza contradictoria, tanto si se lo considera en sí mismo como si se lo relaciona con afirmaciones que Avendaño hace en otros lugares cercanos del Thesaurus. Para juzgar de esto último puede ser suficiente el cotejo con algunas frases del título XI, capítulo II: con base en la miserabilidad de los indios y en la defensa del bien común, el jesuita afirma que “... nunca se da esa pretendida igualdad de derechos, pues siempre hay motivos muy especiales a favor de los indios, con los que se supera el derecho de la otra parte; a saber cuando, prescindiendo de tales consideraciones, el derecho es igual por ambas partes; pues cuando sin esas consideraciones el derecho de los indios es más débil, éste puede equipararse mediante ellas"46. Aparte de reiterar lo que hemos observado ya respecto a la "equidad" o la "igualdad de la justicia", no cabe ahora mejor comentario que transcribir unas palabras de la real cédula de 1593: "antes éstos [los indios] sean más amparados como gente más miserable y de menos defensa...”. Avendaño no recogió estas palabras pero indudablemente las conocía ${ }^{47}$.

\footnotetext{
${ }^{45}$ De esta forma lleva a su molino el agua de la opinión sostenida en general por los doctores, para quienes hay obligación de restituir por el honor herido: puesto que es necesario dar al injuriado prueba de aquello con que su ánimo se aplaque, tratándose de un indio cualquier cosa podría bastar: "apenas hay diferencia de importancia".

${ }^{46}$ Avendaño $I V$, p. 142, núm. 7, énfasis nuestro. Nótese que la idea que expresa Avendaño no está condicionada por el contexto (el capítulo en cuestión tata del administrador de censos de indios) sino que tiene alcance general.

${ }^{47}$ Terminando sus observaciones acerca del estatus de miserabilidad de los indios en la visión de Avendaño, Muñoz García, "Introducción” a Avendaño I, p. 33, escribe lo siguiente: "Aceptando, pues, la figura jurídica del status de miserable..., le falta a nuestro autor la decisión para aplicarla en la práctica
} 
Tanto más nos sorprende la actitud del jesuita cuanto, en un párrafo casi contiguo a los del parágrafo que nos ocupa, ha dejado sentado un juicio tan serio como que los protectores que "por respeto humano" omiten el deber de visitar los hospitales de indios violan "las leyes de la caridad y de la justicia"48.

En cuanto a las contradicciones internas, hemos ido señalándolas al hilo de nuestra exposición. Las recapitulamos ahora con brevedad: amaga Avendaño con un argumento inicial -el de atender más al gentilicio propio que al extraño- que después abandona en beneficio de la opinión común de los autores; si lo primero debía conducir a la igualdad en el trato penal de las injurias, igualdad entendida como lo mínimo exigido por la justicia, lo segundo apunta a la desigualdad en menoscabo de los indios víctimas del delito. La persecución de una idea - los indios son de calidad inferior comparados con los españoles- envuelve una comparación totalmente inadecuada de los primeros con los esclavos. Supuesta la tesis de los indígenas como "clientela del Rey", Avendaño enuncia su consecuencia lógica -"las ofensas de los clientes [léase: a los indios] pueden castigarse con mayor pena que las de los otros"-, pero no la acoge. Frente a la ratio explícita del "rescripto" de 1593 -que no es sino la miserabilidad de los indios-, enumera otros motivos distintos por los cuales lo considera "justo y conveniente": la conversión de los indios, la idea de la clientela y el peligro de que con los naturales se pierdan las grandes riquezas que gracias a ellos se obtienen. El piadoso deseo de llevar el rescripto "lo más posible" a la práctica choca con la afirmación de que su mandato específico "no obliga" en general.

¿Tiene algún sentido absolver de estas faltas al jesuita en atención al método que utiliza? Hasta cierto punto, podemos coincidir con Arvizu cuando señala que en las páginas del Thesaurus se echa en falta la elegantia iuris. El que nos ocupa puede ser, en efecto, uno de esos casos en los que no resulta fácil percibir la claridad expositiva, la sobriedad y la agudeza en el razonamiento que el citado autor supone características del estilo jurídico ${ }^{49}$. Con todo, esta apreciación nos parece insuficiente porque hay otros aspectos que se deben considerar.

Es de advertir, en primer lugar, la cerrazón que Avendaño manifiesta en este tema de las injurias causadas a los indios por los españoles: veinte años después de que Solórzano deplorara el poco respeto y la mala aplicación de que era objeto la real cédula de 1593, pese a la claridad y justificación de su mandato, el jesuita parece empeñado en mantener un criterio demasiado uniforme y más bien anticuado en relación

a casos en los que se contenta con manifestar sentimientos de caridad cristiana. Una caridad que, en tales casos, resulta fatua, por cuanto sólo hubiera podido tener lugar una vez cumplidos los requerimientos de la justicia".

48 Avendaño $I V$, p. 266, núm. 140.

${ }^{49}$ Fernando de Arvizu, "El pensamiento jurídico del P. Diego de Avendaño S.I. Notas de interés para el Derecho Indiano", en IX Congreso del Instituto Internacional de Historia del Derecho Indiano. Actas y Estudios, vol. I, Madrid, 1991, p. 138, donde leemos también este juicio: "puede decirse que [Avendaño] no es jurista: se trata de un teólogo, del moralista que aborda el tratamiento de cuestiones jurídicas". 
con lo que toca a la estimación de los indígenas ${ }^{50}$. Y en segundo lugar, debe resistirse cualquier tentación de colocar su tosca desvirtuación de la ley bajo el cobijo de una $\mathrm{u}$ otra peculiaridad del derecho indiano, ya se quiera pensar en el positivismo, ya en el casuismo y la primacía de la interpretación sobre la aplicación directa de los textos legales, ya en aquel singular expediente de prestar obediencia a la ley pero evitando cumplirla.

Comenzando por esta última posibilidad, no ignoramos la opinión, mencionada por Avendaño por lo menos en dos ocasiones distintas, de que una ley no aceptada carece de valor ${ }^{51}$. Pero tal opinión o doctrina es solamente el segundo de dos vectores que se relacionan dialécticamente. El primero es la ley, y aunque muchas veces el lenguaje legal no fuera inequívocamente imperativo, tampoco faltan los casos en los que cumplía con creces esta característica ${ }^{52}$. Nuestra cédula pertenece sin discusión a este grupo, como para que quepa por lo menos la duda acerca de si es procedente adscribir los devaneos intelectuales del autor del Thesaurus en torno al texto de 1593 a la práctica o el expediente del "se acata, pero no se cumple" 53 . Varias razones abonan esta sospecha: Avendaño señala que la norma es "justa y conveniente" y hasta se permite la finta de abogar por su aplicación "lo más posible" en la práctica, luego difícilmente se habrá tratado, desde su punto de vista, de un supuesto de obediencia sin cumplimiento; de hecho, ni él ni ningún otro autor menciona esta posibilidad. Por otro lado, como indica el caso del cacique abofeteado por un español, parece que la norma sí se cumplió al principio de su vigencia; y no sólo eso, sino que Avendaño, igual que Solórzano, reconoce que la real cédula se había seguido aplicando, si bien menos de lo debido a causa, en parte, de la pusilanimidad de los indios.

${ }^{50}$ Cfr. Mario Soria, "El jesuita Diego de Avendaño: ultramontano y regalista", en Anales de la Fundación Francisco Elías de Tejada 5 (1999) p. 218: "Diríase que tiene el padre Avendaño en mente la situación de los autóctonos en las reducciones jesuitas, o por lo menos la idea de la perpetua tutela de los indios, y que no advierte la asimilación hecha por la corona y el pueblo, incorporando muchos notables indígenas a la aristocracia española, por un lado, y formándose, de otro, un número cada vez mayor de indios puros y mestizos que se han imbuido de la religión y cultura cristianas"; también Muñoz García, "Introducción" a Avendaño I, pp. 166 ss., que deja que sea el lector quien decida si Avendaño debe ser considerado como defensor de los indios o como conservador recalcitrante.

${ }^{51}$ Vid. Avendaño I, p. 285, núm. 155: “... la opinión común, a saber, que una ley no aceptada por el pueblo no es obligatoria"; Avendaño II, p. 479, núm. 198: "No hay nada más claro como que una ley no aceptada en modo alguno tiene valor, y que su inobservancia no se puede castigar".

${ }^{52}$ Baste como ejemplo, especialmente significativo puesto que se refiere al buen tratamiento de los naturales, la cita de Recopilación, lib. 6, tít 10, ley 6: “... y particularmente el cumplimiento, y observancia de cuanto está proveido, y se contiene en las leyes sobre su buen tratamiento, para que tengan cumplido efecto, porque nuestra intención, y voluntad es, que inviolablemente se guarden, y cumplan".

${ }^{53}$ Sobre el tema, especialmente Víctor Tau Anzoátegui, La ley en América hispana. Del descubrimiento a la emancipación, Buenos Aires, 1992, pp. 69 ss.; vid. también Ángel Muñoz García, Diego de Avendaño, 1594-1698: filosofia, moralidad, derecho y politica en el Perú colonial, Lima, 2003, pp. 71 ss.; Francisco Cuena Boy, "Teoría y práctica de la ley. Apuntes sobre tres juristas indianos", en Cuadernos de Historia del Derecho 13 (2006) pp. 15 s. 
Hay razones más sólidas todavía para descartar que la deficiente ejecución de la norma fuera consecuencia del famoso "se obedece, pero no se cumple". Como explica Tau Anzoátegui ${ }^{54}$, esta fórmula no se refería a la mera inobservancia de hecho de las leyes, sino que expresaba la oposición al cumplimiento de una determinada ley por razones fundadas en derecho; además, su virtualidad jurídica era nula sin el oportuno recurso de suplicación que diera cuenta de esas razones al legislador. Ya hemos dicho que en las páginas del Thesaurus no consta nada de esto. En segundo lugar, de 1528 en adelante se observa una reorientación relativa del sistema en el sentido de reemplazar el principio de "obedecer y no cumplir" por el "de obedecer y cumplir" pese a la presentación de la súplica, tendencia ésta que aún dura en época de Avendaño y llega hasta la Recopilación ${ }^{55}$. Por último, desde fechas igual de tempranas se sabe que la suplicación no permite sobreseer el cumplimiento de las leyes favorables a los indios ${ }^{56}$.

El positivismo de Avendaño, su probabilismo y su mentalidad casuista tampoco suministran una explicación plausible, no ya de que la ley fuera poco respetada y mal aplicada en la práctica -éste no es el problema que nos interesa-, sino del insólito modo en que trata, en definitiva, de minimizar su eficacia. El positivismo ${ }^{57}$ puede latir bajo cierto tipo de fórmulas ("porque así lo prevén las leyes" o "[s]on sus palabras, de modo que no puede dudarse de ello") con las que vemos al jesuita zanjar en ocasiones la discusión de tal o cual punto, pero evidentemente está muy lejos de ser el impulso que le mueve a desvirtuar la real cédula de 1593. Tampoco observamos ninguna traza de probablilismo en los razonamientos acerca de esa norma cuyo sinuoso sendero hemos recorrido: frente al tema de las injurias a los indios, no es propósito de nuestro autor sopesar la probabilidad de opiniones distintas para orientar la conciencia del ofensor, por ejemplo, o la del juez. Lo más cercano a un planteamiento de esta naturaleza es su aseveración de que el asunto "se encuentra actualmente en situación en la que el rescripto no obliga, en general, cuanto al mencionado exceso" 58 , pero el parecido es puramente verbal y no explica nada; ello por dos razones: porque Avendaño no tenía que habérselas con una ley oscura de la que pudiera decir, en el plano moral, aquello de lex dubia non obligat $t^{59}$; y porque su afirmación de que la ley no obliga en cuanto al exceso - es decir, en cuanto al mayor rigor con que ordena castigar a los españoles- se refiere, en consecuencia, rigurosamente al plano de la normatividad exterior o legal. Finalmente, en cuanto al argumento del casuismo, tan

\footnotetext{
${ }^{54}$ Tau Anzoátegui, op. cit., pp. 74 s.

${ }^{55}$ Tau Anzoátegui, op. cit., pp. 84 ss.; cfr. especialmente Recopilación, lib. 2, tít. 1, ley 24.

${ }^{56}$ Tau Anzoátegui, op. cit., pp. 96 s.; cfr. Recopilación, lib. 2, tít. 1, ley 5.

${ }^{57}$ En el sentido que explica Muñoz García, Diego de Avendaño cit., pp. 69 s., de dar prioridad a las disposiciones del derecho municipal ("normas derivadas de la experiencia misma y no de principios axiomáticos") por encima, por ejemplo, del derecho romano.

${ }^{58}$ Avendaño, p. 275, núm. 150.

${ }^{59}$ Cfr. Muñoz García, "Introducción” a Avendaño I, pp. 37 ss.; Id., Diego de Avendaño cit., pp. 63 ss.; Id., "Introducción" a Avendaño II, pp. 29 ss.
} 
socorrido, conviene tener claro desde el principio que esta orientación no consiste ni mucho menos en un manejo caprichoso de los textos legales ${ }^{60}$. Las cosas no fueron nunca así ni entre los juristas romanos ni tampoco entre los juristas indianos ${ }^{61}$. El casuismo utiliza una serie de técnicas muy complejas que ante todo, por lo que toca a las leyes, se proponen su más perfecta inteligencia en orden a una aplicación justa. Y el casuismo, por otro lado, tiene un curso quizás más fácil y natural cuando el material legislativo al que se enfrenta el intérprete resulta ser casuista desde su propia formulación. Valgan estas precisiones, que por supuesto no agotan el tema ${ }^{62}$, para ratificarnos ahora en que Avendaño no interpreta con mentalidad y técnica de casuista la real cédula a la que se refieren sus comentarios. Lo que hace con ella en realidad, sin técnica ni elaboración propiamente jurídicas, es propugnar la conversión de una ley general en su contrario; es decir, en una norma de aplicación excepcional, viniendo dadas las excepciones, curiosamente, por la singularidad que pudiera suponer la comisión de una injuria especialmente grave o por un juicio de oportunidad acerca del carácter ejemplar de la «vindicta» ${ }^{63}$. Éste es el único atisbo de casuismo que encontramos en las pocas páginas del Thesaurus que hemos analizado, pero no creemos exagerado afirmar que se trata de un casuismo muy poco respetuoso y hasta ilegítimo; de algo que entra, por la puerta y con el disfraz del trabajo intelectual, más bien en el ámbito de la desobediencia a una ley en vigor ${ }^{64}$.

Todo ello, en un autor perfectamente consciente de que, puesto que "las leyes se hacen generalmente de acuerdo a los acontecimientos, cualesquiera indios, cuando se trata de su favor, han de ser considerados personas miserables" ${ }^{65}$.

${ }^{60}$ Vid. Cuena Boy, “Teoría y práctica de la ley” cit., pp. 13, 18, 28 s, passim.

${ }^{61}$ Sobre los juristas romanos es obligado remitir a Alejandro Guzmán Brito, Historia de la interpretación de las normas en el derecho romano, Santiago de Chile, 2000; hay una segunda edición publicada en 2011 en México; para los siglos XVI y XVII, vid. Jan Schröder, Recht als Wissenschaft. Geschichte der juristischen Methode vom Humanismus bis zur historischen Schule, München, 2001.

${ }^{62}$ Respecto al casuismo de los juristas indianos es fundamental el estudio de Víctor Tau Anzoátegui, Casuismo y sistema. Indagación histórica sobre el espiritu del derecho indiano, Buenos Aires, 1992, en especial el cap. VI, I sobre "La ley dentro de un orden casuista"(pp. 319-358), y el cap. VIII, I sobre "La aplicación en un orden casuista" (pp. 486-541).

${ }^{63}$ Avendaño, p. 275, núm. 150.

${ }^{64}$ Una real cédula de 12 de diciembre de 1619 expresaba este reproche: “... diversas ordenanzas, cédulas y otros despachos para la conservación de los indios y que como personas miserables y que están debajo de mi protección, no reciban agravio, y que a vos y a las demás justicias os toca el cuidado del cumplimiento de ellas...; sin embargo de esto, cada día se tienen semejantes quejas, causadas de menospreciar y derogar las leyes, órdenes y cédulas y de falta de ejecución de ellas..."; vid. R. Konetzke, Colección de documentos para la historia de la formación social de Hispanoamérica, 1493-1810, vol. II/1 (15931659), Madrid, 1958, pp. 245 s.

${ }^{65}$ Avendaño IV, p. 267, núm. 141, énfasis nuestro; cfr. Avendaño $V$, p. 94, núm. 1: “en orden al recto y pacífico gobierno de los indios, [los reyes] han dado ya muchas disposiciones que, si se cumplieran, no habría que desear más. Que su cumplimiento esté vigente está también previsto en sus repetidas advertencias". 
Por último, a este simulacro de interpretación le hemos dado un adjetivo cuyo alcance nos interesa precisar. Al decir que los párrafos que hemos examinado son una página "característica" de Avendaño, no tenemos la intención de extender nuestras críticas al muy extenso conjunto del Thesaurus Indicus, su obra mayor. La pericia con la que el jesuita sabe conducir la interpretación de las leyes, los conocimientos jurídicos que le adornan y la capacidad de que hace gala para fundirlos con criterios morales, teológicos o de cualquier otra especie, todo esto es indudable aun a pesar de que el probabilismo que constituye el norte de sus reflexiones depare resultados no tan aceptables a veces en el plano de la ley y el derecho ${ }^{66}$. Después de todo, Avendaño no habla principalmente como jurista sino como moralista. Sin embargo, en ocasiones da la impresión de que el moralista Avendaño se sirve ad líbitum de sus artes de probabilista para admitir cosas inadmisibles; es decir, da la impresión de que cae en parcialidad intelectual. En este sentido, y sólo en este sentido, nos parece posible defender que sus razones acerca de "[s]i las injurias hechas a los indios deben ser castigadas más severamente que las inferidas a otros" componen efectivamente una página característica de nuestro jesuita.

${ }^{66}$ Cfr. Ballón, op. cit., pp. 36 s.: "El asunto verdaderamente importante aquí parace ser el traslado de los juicios morales desde el terreno teórico (explicación por causas y leyes) al terreno de la opinión (explicación por motivos y circunstancias); lo que convierte los asuntos morales, jurídicos o políticos (o al menos una gran parte de ellos) en problemas de intencionalidad pragmática y de comunicación o entendimiento intersubjetivo". 